\title{
Behaviour and Degenerative Changes in the Basal Forebrain Systems of Aged Rats (12 Months Old) after Levo-Acetyl-Carnitine Treatments
}

\author{
Roberta Freddi ${ }^{1,2}$, Piergiorgio Duca ${ }^{1}$, Maurizio Mariotti ${ }^{1}$, Ivana Gritti ${ }^{1 *}$ \\ ${ }^{1}$ Department of Clinical Science-Luigi Sacco, School of Medicine and Surgery, University of Milan, Milano, Italy \\ ${ }^{2}$ Complex Structure-Anatomia Patologica, A.S.L.-VCO, Verbania, Italy \\ Email: "Ivana.Grittti@unimi.it
}

Received June 30, 2011; revised November 22, 2011; accepted December 7, 2011

\begin{abstract}
One group of six male control rats [12 months old] and one group of six male rats of the same age, singularly maintained in a cage, and treated with acetyl-L-carnitine-HCl [(gamma-trimethyl-beta-acetyl-butyrobetaine-HCl: Sigma-Tau code ST200 or ALCAR: $60 \mathrm{mg} / \mathrm{kg} / \mathrm{day}[7] / \mathrm{po})]$ for six months were tested in the spatial learning $/ \mathrm{memory}$ Morris mazewater task and for atrophy and cell loss in seven myelo- and cytostructurally defined basal forebrain (BF) cholinergic regions [Freddi et al., 2009]. Coronal sections $25 \mu \mathrm{m}$ thick were cut through the BF regions and processed every 200 $\mu \mathrm{m}$ for choline acetyltransferase (ChAT) immunohistochemistry. The ALCAR-treated rats had significantly shorter exit times on the Morris maze-water task test than the control rats (average \pm SD $28.3 \pm 12.4 \mathrm{~s}$ vs. $61.16 \pm 4.67 \mathrm{~s} ; \mathrm{t}=6.07$, $\mathrm{DOF}=10, \mathrm{P}=0.0001$ ). Degenerative morphological changes in the BF ChAT-positive cells were observed in the substantia innominata pars anterior of the control rats but not in the treated animals $(\mathrm{P}<0.05)$. In the BF, the counted and estimated average number of ChAT + cells in the 12-month-old ALCAR-treated rats (ChAT-ALCAR-12+ [Nos. 2,3,4]) was higher but not significantly $(15.288 \pm 3281)$ than that counted and estimated in the 12-month-old control rats [(ChAT-CT-12 [Nos. 1,2,3]) $(11.508 \pm 3868), \mathrm{t}=1.82$, DOF $=10, \mathrm{P}=0.319]$. In the substantia innominata pars posterior, the ChAT + cells were significantly more numerous $(\mathrm{P}<0.05)$ in the 12 -month-old ALCAR-treated rats $(\mathrm{ChAT}$ ALCAR-12 + [Nos. 2,3,4]) than in the control rats (ChAT-CT-12 [Nos. 1,2,3]). Above all, these results demonstrate that treatment with ALCAR from the age of 6 up to 12 months significantly attenuated spatial learning/memory impairment on the Morris maze-water behavioral task $(\mathrm{P}<0.001)$ and also importantly reduced degeneration in size and number of cholinergic cells in the nucleus basalis magnocellularis of the BF. Accordingly, the surviving cholinergic neurons found in the BF of the ALCAR-treated rats might play an important role in modulating cortical activity and facilitating processes of attention, learning and memory.
\end{abstract}

Keywords: Acetyl-L-Carnitine-HCl; Ageing; Choline Acetyltransferase Neurons; Substantia Innominata; Morris Maze-Water Task

\section{Introduction}

Acetyl-L-carnitine ([ALCAR] gamma-trimethyl-beta-acetyl-butyrobetaine-hydrochloride, Sigma-Tau code: ST200) is the metabolically active form of acetylcarnitine present in the central nervous system (CNS). ALCAR acts as a shuttle for long-chain fatty acids between the cytoplasm and the mitochondria, is involved in the production of cellular energy and the removal of toxic accumulation of fatty acids from the mitochondria. It is actively transported across the blood-brain barrier and displays affinities for GABAergic and L-glutamate carriers [1]. Acetyl-L-carnitine is a source of acetyl groups and acts as a partial cholinergic agonist synergistically with ACh and L-glu-

"Corresponding author. tamate, increasing the firing rate of rat neocortical neurons [2], thus working in the CNS [3-9].

Rodents present an age-related decline in nerve growth factor (NGF) and basal forebrain (BF) cholinergic neurons, as well as in learning and memory ability $[10,11]$. Acetyl-L-carnitine protects the CNS and NGF [8,9,12-13], improves cognitive deficits, and very importantly reduces rat mortality $[14,15]$. Rats and mice show an age-dependent decline in ACh and cell loss in the septo-hippocampal and BF regions [16-19]. Contrasting data about the age-dependent cholinergic cell $\mathrm{BF}$ decline have been reported by Horneberger et al. [20], who noted that aging causes a progressive shrinkage of AChE positive neurons in the BF nuclei, which was most pronounced in the nucleus basalis magnocellularis; however, the number of 
cells remained unchanged.

To date, no studies have investigated in 12-month-old rats, untreated and treated with ALCAR, for the severity and the extension of cholinergic cell loss in the seven myelo- and cytoarchitecturally defined BF regions which comprise [15]: the medial septum (MS) and diagonal band of Broca (DBB), the magnocellular preoptic nucleus (MC$\mathrm{PO}$ ), the olfactory tubercle (Otu), the substantia innominata pars anterior (SIa, also called the ventral pallidum), the substantia innominata pars posterior (SIp, also called the extended amygdala), and the globus pallidus (GP), where basal-cortical neurons projecting to the meso- and isocortex $[21,22]$ intermingle with the BF cells projecting into the caudal hypothalamus [23].

Although cholinergic cells account for only 5\% - 6\% of the total population of the BF, this study focused on: 1) the topographical location and severity of cholinergic deficit in 12-month-old rats with impaired performance on the spatial/learning Morris water-maze test; and 2) the effect of acetyl-L-carnitine treatment on rats aged from 6 to 12 months to see whether this neuropsychopharmacological compound can significantly attenuate spatial learning/memory impairment on the Morris maze-water task [13] and significantly reduce degeneration of the largest cholinergic neurons in the seven myelo- and cytoarchitecturally defined BF regions [15,24-26].

\section{Methods}

\subsection{Animals}

All experiments were carried out in accordance with Directive 86/609/EEC regulating experimental animal care and with the aim to maximally reduce stress, suffering and the number of animals used $[15,25]$.

Twelve male Sprague-Dawley Ico rats (OFA-SD-IOPS Caw) (IFFACredo, Italy) (age, 6 months; approximate body weight $545 \pm 20 \mathrm{~g}$ ) bought by Sigma-Tau (Rome, Italy) were singularly maintained in cages at the SigmaTau laboratory, given food and water ad libitum and kept in a $12 / 12 \mathrm{~h}$ light/dark cycle, at $22^{\circ} \mathrm{C} \pm 3^{\circ} \mathrm{C}$, humidity $50 \%$ $\pm 15 \%$, in a specific pathogen-free (SPF) area where they were checked regularly for common rat pathogens and general health so as to exclude pathological states which could interfere with the testing phase.

Similar to Markowska et al. [14], the treatment group was six 6-month-old rats given $60 \mathrm{mg} / \mathrm{kg}$ of ALCAR [(gamma-trimethyl-beta-acetyl-butyrobetaine-HCl: Sig-maTau code ST200)] in their drinking water every day a week for six months (ChAT-ALCAR-12: Nos. 1, 2, 3, 4, 5,6 ); the six control rats received only water and food ad libitum from the age of 6 to 12 months (ChAT-CT-12: Nos. 1, 2, 3, 4, 5, 6). The total volume of ALCAR solution was calculated on the basis of the animals' daily water consumption, and the total amount of ALCAR given was calculated in relation to each animal's weight [16]. To ensure that each animal received $60 \mathrm{mg} / \mathrm{kg}$ of ALCAR, both parameters were checked daily during the experiments. The concentration of ALCAR consumption was approximately $6 \%$ on mass basis. However, we do not know exactly the mortality rate of the colonies of rats treated with ALCAR at the Sigma-Tau laboratories at the Pomezia Research Centre (Rome, Italy). Markowska and co-authors reported that the mortality ratio of the rats, with about the same body weight, at the Gerontology Research Centre, at the Johns Hopkins University, Baltimore, and at the University of Colorado, was $2-3$ rats out of 15 treated with $75 \mathrm{mg} / \mathrm{kg} /$ day $/$ os of ALCAR [14] (see Table 2 and Figure 2).

\subsection{Behavioral Morris Water-Maze Test}

After six months of ALCAR treatment (or not), all twelve 12-month-old rats were tested, during daylight, for spatial learning/memory on the Morris water-maze task [27]. The test apparatus consisted of a large round plastic tank (130 $\mathrm{cm}$ in diameter and $45 \mathrm{~cm}$ high) filled to a depth of $40 \mathrm{~cm}$ with 770 litres of water kept at $24^{\circ} \mathrm{C}$. The test apparatus was divided into four quadrants by four points positioned at equal distances along the edge and arbitrarily labelled North, South, East and West. A white escape platform $(10 \mathrm{~cm}$ in diameter) was located $1 \mathrm{~cm}$ beneath the water surface in the middle of the NW quadrant, and kept at the same position in the pool at all times during the experiment. The pool was placed in a corner of a room containing several extra-maze cues (objects) which the animals could use as reference points to locate the platform. Dried milk powder was added to the water to make it opaque. The day before each experiment, the platform was removed, the water was changed, and the rat was allowed to swim freely for 3 minutes so as to become familiar with the surroundings. On test days the animals were placed in the tank at one of the four different equidistant starting points along the edge and timed to see how long they took to reach the platform. After the rats had found the platform, they were left on it for 30 seconds before beginning a new trial. Four trials $\mathrm{s}_{(\mathrm{a}, \mathrm{b}, \mathrm{c}, \mathrm{d})}$ were carried out per session(s) [S1 + S2 + S3 + S4] [15]. The experiment was divided into two phases: an acquisition phase consisting of eight sessions, and a retention phase, presented in this study, consisting of four sessions.

We calculated the average time (in s) that each animal took to climb onto the platform during the retention phase of four sessions $\left[\mathrm{S} 1_{(\mathrm{a}, \mathrm{b}, \mathrm{c}, \mathrm{d})}+\mathrm{S} 2_{(\mathrm{a}, \mathrm{b}, \mathrm{c}, \mathrm{d})}+\mathrm{S} 3_{(\mathrm{a}, \mathrm{b}, \mathrm{c}, \mathrm{d})}+\mathrm{S} 4_{(\mathrm{a}, \mathrm{b},}\right.$ $\mathrm{c}, \mathrm{d})]$ : the last test was performed before death by aortic perfusion. The average time needed to escape onto the platform (in seconds (s)) was statistically analyzed using two- and one-way ANOVA and post-hoc Student's t-test multiple comparison of the means. 


\subsection{Surgery and Perfusion}

After completing the behavioral tests at the Sigma-Tau laboratory, the five control (ChAT-CT-12: Nos. 1,2,3,4,5 (body weight, $713 \pm 36.5 \mathrm{~g}$ ) and the four ALCAR-treated (ChAT-ALCAR-12: Nos. 1, 2, 3, 4 (body weight, $730 \pm$ $73.5 \mathrm{~g}$ ) male Sprague-Dawley Ico rats were anaesthetized with chloral hydrate $(278 \pm 15 \mathrm{mg} / \mathrm{ip})$ for surgery and perfusion at the Medical School of the University of Milan (Milan, Italy). One control rat (ChAT-CT-12: No. 6) and 2 ALCAR-treated rats (ChAT-ALCAR-12: Nos. 5, 6) were delivered to the Pharmacy School of the University of Milan (Milan, Italy) for another parallel study.

As previously reported [15], the brains of the five control (ChAT-CT-12: Nos. 1,2,3,4,5 (body weight, $713 \pm$ $36.5 \mathrm{~g}$ ) and the four ALCAR-treated (ChAT-ALCAR-12: Nos. 1, 2, 3, 4 (body weight, $730 \pm 73.5$ g) male SpragueDawley Ico rats were fixed by perfusion through the ascending aorta, first with a phosphate buffered solution [(PBS; $0.1 \mathrm{M}, \mathrm{pH} 7.4$, containing $20 \mathrm{mM} \mathrm{MgCl} 2)(<100$ $\mathrm{ml}$ within $30 \mathrm{~s})$ ], then with a fixative solution containing $3 \%$ paraformaldehyde, $0.2 \%$ picric acid and $0.05 \%$ glutaraldehyde ( $\mathrm{pH} 7.4$ ) in $0.1 \mathrm{M}$ PBS) (approximately 1000 $\mathrm{ml}$ over $30 \mathrm{~min}$ ), and finally with $10 \%$ sucrose PBS (pH 7.4) (approximately $250 \mathrm{ml}$ over $15 \mathrm{~min}$ ). All solutions were perfused at a temperature between $10^{\circ} \mathrm{C}$ and $18^{\circ} \mathrm{C}$. The brains were removed, cut into two coronal blocks, immersed overnight, and shaken at $4^{\circ} \mathrm{C}$ in $30 \%$ sucrose/ $\mathrm{PBS}$, then frozen at $-50^{\circ} \mathrm{C}$ in liquid freon and stored at $-80^{\circ} \mathrm{C}$.

\subsection{Immunocytochemistry}

As previously published [15,21-24], coronal brain sections $25 \mu \mathrm{m}$ thick of the ChAT-CT-12+: Nos. 1,2,3 and of the ChAT-ALCAR-12+: Nos. 2,3,4 rats were cut on a freezing microtome and collected every $200 \mu \mathrm{m}$ in PBS $(\mathrm{pH}$ 7.3). The sections were processed for visualization of choline acetyl transferase (ChAT + ) labeling using the peroxidase antiperoxidase (PAP) technique with a ChAT monoclonal antibody (1:4) prepared in rats (Boehringer Mannheim, Germany). The ChAT antibody was obtained by fusing mouse myeloma cells (X63Ag8.653) with spleen cells of Wistar rats after immunization with highly purified choline acetyltransferase from pig brains. The sections were incubated overnight, first with the primary antibody, then with a rabbit anti-rat antibody (1:50, ICN, Italy) for $45 \mathrm{~min}$, and finally with rat PAP (1:50 - 1:75) (Sternberger Monoclonals Inc., USA) for $45 \mathrm{~min}$. The last two steps were repeated in a double-bridge procedure. The primary and secondary antibodies were diluted in Tris solution (TS, $0.1 \mathrm{M}$ ) containing $1 \%$ normal rabbit serum $(\mathrm{NRbS})$ which was also used for rinses between incubations. Before incubation, the sections were placed in TS containing a higher concentration of bovine serum albu- min (BSA 10\%) for blocking. The peroxidase (PAP) was revealed by 6 min incubation with $0.05 \% 3^{\prime}, 3^{\prime}$ diaminobenzidine (DAB) and $0.01 \%$ hydrogen peroxidase $\left(\mathrm{H}_{2} \mathrm{O}_{2}\right)$ in Tris water (TW). Control sections were incubated without the primary antibody and processed with the seconddary antiserum, PAP, and DAB.

\subsection{Estimation and Morphological Image Analysis of the ChAT+ Cells in the BF}

As previously reported [15,21-24], to map and estimate the BF ChAT-immunoreactive cells in the BF of the 3 control (ChAT-CT-12+: Nos. 1, 2, 3) and of the 3 ALCARtreated (ChAT-ALCAR-12+: Nos. 2, 3, 4) rats-where the perfusion and immunohistochemistry were best developed - we used a Biocom image-analysis system (Biocom, Paris, France) with a computer-based atlas of cholinergic BF cell groups. The image-analysis system consisted of a Leitz Dialux microscope equipped with an $\mathrm{x} / \mathrm{y}$ movement-sensitive stage and a video camera (COHU) connected to a Compaq Deskpro/25 M computer. The atlas consisted of 6 templates $(800 \mu \mathrm{m}$ apart) extending from AP levels A10.9 - A6.9 through the BF regions, divided into seven contours distributed over more than one level. Labeled ChAT + cells were mapped [ChAT-CT12+: Nos. 1,2,3 and ChAT-ALCAR-12+: Nos. 2, 3, 4] or drawn [ChAT-CT-12+: No. 1 and ChAT-ALCAR-12+: No. 2] in the seven subregions of the BF by fitting each section to the appropriate atlas template at low power $(2.5 \times$ objective $)$ and tracing or indicating the ChATCT-12+: Nos.1, 2, 3 + cells and the ChAT-ALCAR-12+: Nos. 2, 3, $4+$ cells of the rats using a mouse-driven cur= sor at high power $(40 \times$ objective $)$.

\subsection{Statistical Analysis}

As previously described [15,21-24], the morphometric measurements of the ChAT-CT-12+ and the ChAT-ALCAR-12+ cell groups under study were averaged for each $\mathrm{BF}$ nucleus and are presented here, as previously described for 2 rats: one control (ChAT-CT-12+ No. 1) and one ALCAR-treated (ChAT-ALCAR-12+ No. 2) rat. Data were analyzed with Student's t-test.

Abercrombie's estimation of cholinergic cells has recently been demonstrated not to differ significantly from stereological estimation of cholinergic cells $[24,25]$. Therefore, we performed average cell counts per 3 rats from each group [ChAT-CT-12+: Nos. 1, 2, 3 and ChAT-ALCAR-12+: Nos. 2, 3, 4] in the seven cyto- and myelostructurally defined $\mathrm{BF}$ regions [25] and computed the total numbers by using Abercrombie's formula (Abercrombie 1946), viz. using the average morphometric measurements of the large diameters of the ChAT-CT-12+ (No. 1) and ChAT-ALCAR-12+ (No. 2) cells calculated from the longest diameter of the nuclei. 
The computer-based maps through the BF were completed for publication using the Corel Draw 8 software program.

\section{Results}

\subsection{Morris Behavioral Water-Maze Test}

The average exit time in the last four sessions $\left(\mathrm{S}_{(\mathrm{a}, \mathrm{b}, \mathrm{c}, \mathrm{d})}+\right.$ $\left.\mathrm{S} 2_{(\mathrm{a}, \mathrm{b}, \mathrm{c}, \mathrm{d})}+\mathrm{S} 3_{(\mathrm{a}, \mathrm{b}, \mathrm{c}, \mathrm{d})}+\mathrm{S} 4_{(\mathrm{a}, \mathrm{b}, \mathrm{c}, \mathrm{d})}\right)$ of the final trials during the retention phase of spatial learning and memory consolidation of the Morris water-maze test [13], i.e., the time taken to reach the platform, was significantly greater on average in the 12-month-old control rats [ChATCT-12+ (Nos. 1, 2, 3) $(61.16 \pm 4.67$ (s)] than in the 12month-old ALCAR-treated rats [ChAT-ALCAR-12+ (Nos. $2,3,4)(28.30 \pm 12.40$ (s)] (Table 1). The control animals had consistently longer exit times. Prolonged ALCAR treatment of the rats, from the age of 6 to 12 months, very significantly attenuated the impairment in spatial learning $(\mathrm{P}<0.0001)$. Moreover, the exit times in the last four sessions of the final trial indicate that the aged ALCARtreated rats showed the most significant drop in exit time in the last session [13] (see Table 1 and Figure 2).

\subsection{Localization of ChAT Basal Forebrain Neurons}

Stained BF sections: in the 12-month old controls [ChATCT-12+ (Nos. 1, 2, 3)] and in the ALCAR-treated [ChATALCAR-12+ (Nos. 2, 3, 4)] rats, the cells containing ChAT were evident by a dark floccular brown staining produced by DAB. As previously reported [24], ChAT + cel-

Table 1. Time taken by 12-month-old control rats (ChATCT-12; Nos. 1, 2, 3) and ALCAR-treated 12-month-old rats (ChAT-ALCAR-12; Nos. 2, 3, 4) to find the platform (seconds) on the Morris water-maze test.

\begin{tabular}{|c|c|c|c|c|}
\hline \multicolumn{5}{|c|}{ Time taken to find the platform (seconds) } \\
\hline & \multicolumn{3}{|c|}{ Trial Exit time (s) } & \multirow{2}{*}{$\begin{array}{l}\text { Exit time (s) } \\
\text { Trial S1-S4 } \\
\text { Mean } \pm \text { SD }\end{array}$} \\
\hline $\mathrm{S} 1_{(\mathrm{a}, \mathrm{b}, \mathrm{c}, \mathrm{d})}$ & $\mathrm{S} 2_{(\mathrm{a}, \mathrm{b}, \mathrm{c}, \mathrm{d})}$ & $\mathrm{S} 3_{(\mathrm{a}, \mathrm{b}, \mathrm{c}, \mathrm{d})}$ & $\mathrm{S} 4_{(\mathrm{a}, \mathrm{b}, \mathrm{c}, \mathrm{d})}$ & \\
\hline \multicolumn{5}{|l|}{ ChAT-CT-12; Nos. 1, 2, 3} \\
\hline Average $\quad 67.0$ & 62.3 & 59.3 & 56.0 & 61.16 \\
\hline 1.73 & 2.51 & 4.72 & 6.00 & 4.67 \\
\hline \multicolumn{5}{|c|}{$\begin{array}{l}\text { ALCAR } \\
\text { ChAT-ALCAR-12; Nos. 2, 3, } 4\end{array}$} \\
\hline Average $\quad 42.3$ & 33 & & & \\
\hline 2.08 & 1.15 & 1.52 & 2.51 & 40 \\
\hline \multicolumn{5}{|c|}{$\begin{array}{l}\text { 1) Two-way ANOVA showed that the ALCAR-treated rats (ChAT-AL- } \\
\text { CAR-12; Nos. } 2,3,4) \text { had significantly shorter exit times than the untreated } \\
\text { control rats }(\text { ChAT-CT-12; Nos. } 1,2,3) \text { : across groups }(\mathrm{P}=0.0001) \text {, sections } \\
(\mathrm{P}=0.0001) \text { and between group and sections }(\mathrm{P}=0.0013) ; 2) \text { One-way } \\
\text { ANOVA for each group showed that all ALCAR-treated rats (ChAT-AL- } \\
\text { CAR-12; Nos. } 2,3,4) \text { had significantly shorter exit times than the untreated } \\
\text { control rats (ChAT-CT-12; Nos. } 1,2,3)(\mathrm{P}=0.0001) ; 3) \text { Rats in the same } \\
\text { group (ChAT-CT-12; Nos. } 1,2,3 \text { and ChAT-ALCAR-12; Nos. } 2,3,4) \text { took } \\
\text { approximately the same time to reach the platform. }\end{array}$} \\
\hline
\end{tabular}

ls were examined only if they were visible as whole cells containing nuclei with at least 3 dendrites.

In the BF, the ChAT+ cells in the control rats (ChATCT-12+: Nos. 1, 2, 4) (Figure 1) and the ChAT+ cells in the ALCAR-treated rats (ChAT-ALCAR-12: Nos. 2, 3, 4) (Figure 2) were distributed throughout the myelo-cytoarchitectonic subregions: the medial septum (MS), the diagonal band of Broca (DBB), the magnocellular preoptic nucleus (MCPO), the olfactory tubercle (OTu), the substantia innominata pars anterior (SIa), also called the ventral pallidum, the substantia innominata pars posterior (SIp), also called the sublenticular substantia innominata

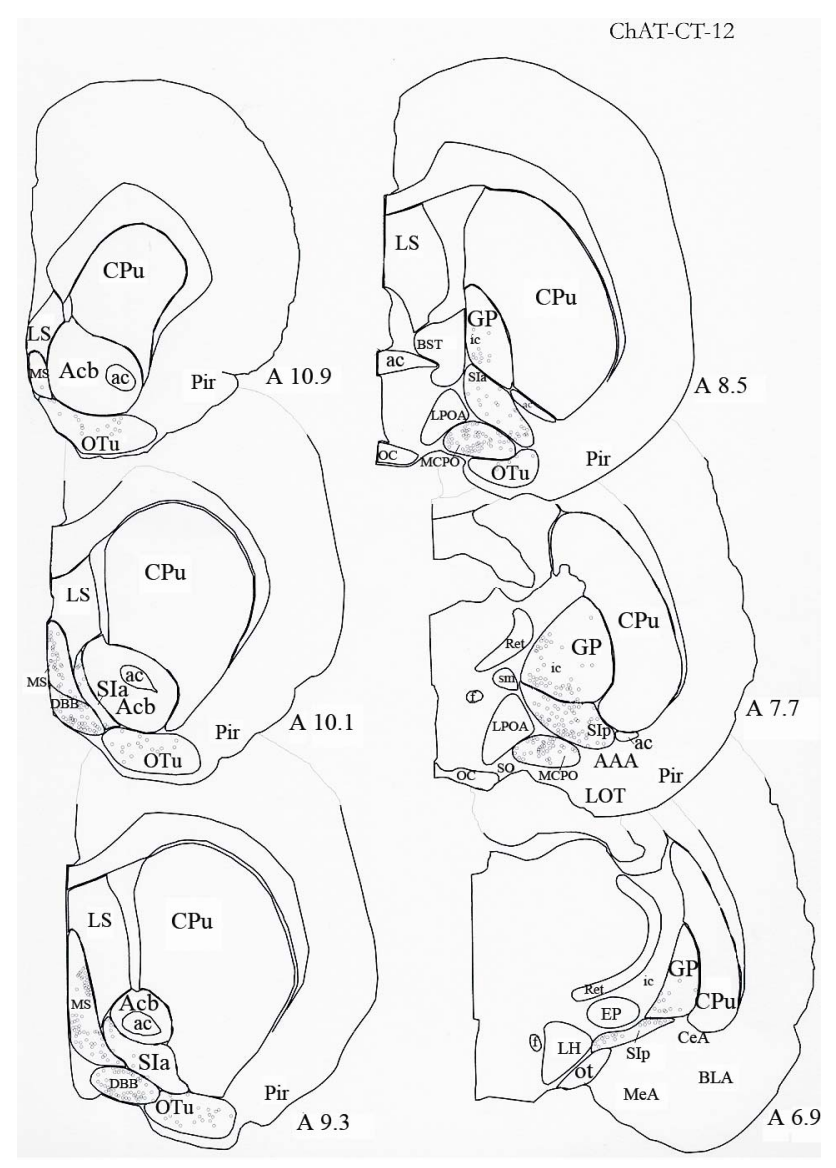

AAA: anterior amygdaloid area; ac: anterior commissure; Acb: accumbens nucleus; BLA: basolateral amygdaloid nucleus; BST: bed nucleus of the stria terminalis; CeA: central amygdaloid nucleus; CPu: caudate putamen; DBB: diagonal band of Broca nucleus; EP: entopeduncularis nucleus; f: fornix; GP: globus pallidus; ic: internal capsule; LH: lateral hypothalamus area; LOT: lateral olfactory tract; LPOA: lateral preoptic area; LS: lateral septum; MCPO: magno cellular preoptic nucleus; MeA: medial amygdaloid nucleus; MS: medial septum; oc: optic chiasm; ot: optic tract; OTu: olfactory tubercle; Pir: piriform cortex; Ret: reticularis nucleus; SIa: substantia innominata pars anterior; SIp: substantia innominata pars posterior; sm: stria medullaris; SO: supra optic nucleus

Figure 1. Computer atlas figure showing six levels of the BF. The contours of the major subregions were drawn with the aid of a computer image-analysis system (Biocom, Paris, France). Distribution of ChAT+ cells in the ChAT-CT-12+ No. 1 rat was directly mapped at high magnification $(40 \times)$ on the atlas template. Each symbol represents one labeled cell. 

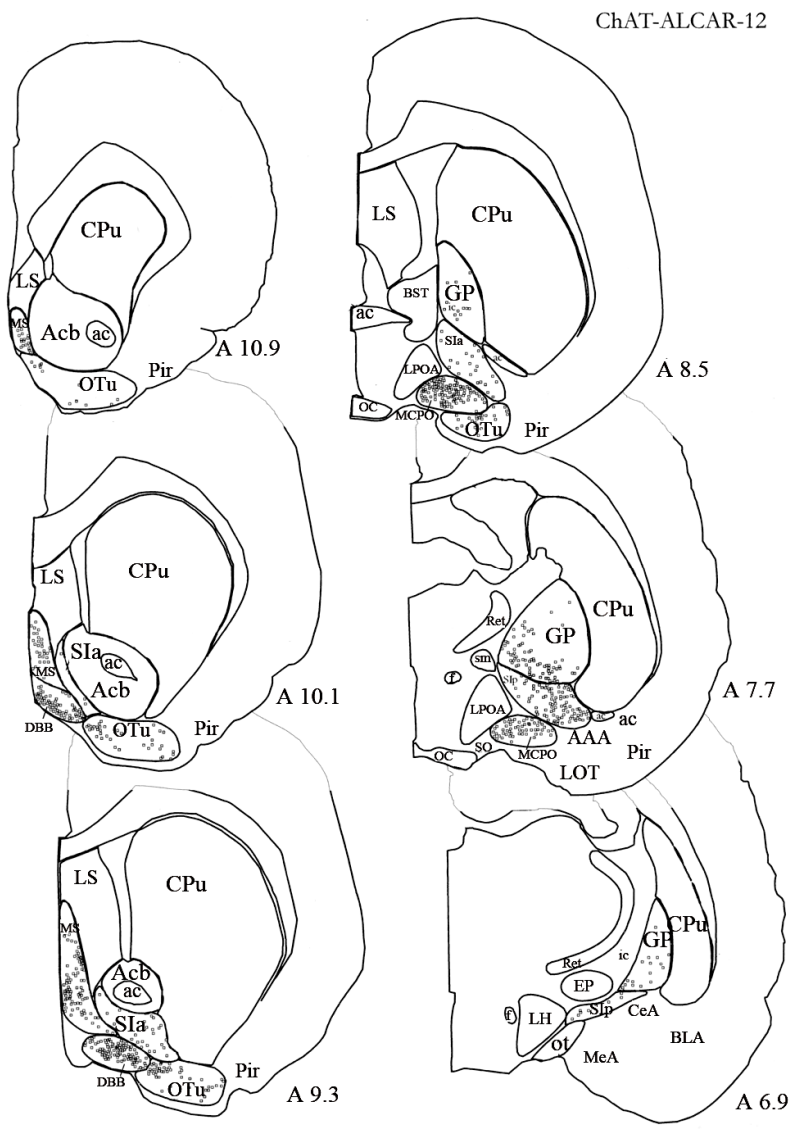

AAA: anterior amygdaloid area; ac: anterior commissure; Acb: accumbens nucleus; BLA: basolateral amygdaloid nucleus; BST: bed nucleus of the stria terminalis; $\mathrm{CeA}$ : central amygdaloid nucleus; $\mathrm{CPu}$ : caudate putamen; DBB: diagonal band of Broca nucleus; EP: entopeduncularis nucleus; f: fornix; GP: globus pallidus; ic: internal capsule; LH: lateral hypothalamus area; LOT: lateral olfactory tract; LPOA: lateral preoptic area; LS: lateral septum; MCPO: magno cellular preoptic nucleus; MeA: medial amygdaloid nucleus; MS: medial septum; oc: optic chiasm; ot: optic tract; OTu: olfactory tubercle; Pir: piriform cortex; Ret: reticularis nucleus; SIa: substantia innominata pars anterior; SIp: substantia innominata pars posterior; sm: stria medullaris; SO: supra optic nucleus

Figure 2. Computer atlas figure showing six levels of the BF. The contours of the major subregions were drawn with the aid of a computer image-analysis system (Biocom, Paris, France). Distribution of ChAT+ cells in the ChAT-ALCAR12+ No. 2 treated rat was directly mapped at high magnification $(40 \times)$ on the atlas template. Each symbol represents one labeled cell.

or extended amygdala, and the globus pallidus (GP). Throughout the BF, the ChAT + cells of the 12-month-old control and ALCAR-treated rats were found to be oriented according to the principal direction of the passing fibers within the seven BF subregions.

The ChAT+ cells in the BF of the control rat [ChATCT-12 + (No. 1)] varied from small to medium in size, ranging from 11.9 to $21.9 \mu \mathrm{m}$ in large diameter; they formed a population with one mode, with an average large diameter of $16.8 \pm 2.0 \mu \mathrm{m}$ (Table 2).

In the ALCAR-treated rat [ChAT-ALCAR-12+ (No.
2)] (Table 2), the ChAT+ cells varied in size and shape, being fusiform, oval or polygonal and correspondingly bi- or multipolar across the different BF regions. Measurements of the cell soma showed that the ChAT+ cells varied from small to large, ranging from 9 to $32.5 \mu \mathrm{m}$ in large diameter, and formed a population with one mode. Indeed, the majority of the ChAT+ cells had medium to large-sized neurons with a long diameter of $17.9 \pm 1.8 \mu \mathrm{m}$. In summary, the average large diameter of the ChAT + cells recorded in the control rat [ChAT-CT-12+ (No. 1)] was significantly smaller than the average of the large diameter of the ChAT+ cells measured in the ALCARtreated rat [ChAT-ALCAR-12+ (No. 2)] (Table 2). Although the cell population of the ChAT-CT-12+ (No. 1) and of the ChAT-ALCAR-12+ (No. 2) overlapped in surface area and diameter, the population of the ChAT$\mathrm{CT}-12+$ (No. 1) was significantly $(\mathrm{P}<0.05)$ smaller than that of the ChAT + cells of the ALCAR-treated rat [ChATALCAR-12+ (No. 2)] (Table 2).

Throughout the BF, the ChAT+ cells were more numerous in the ALCAR-treated rats [ChAT-ALCAR-12+ (Nos. 2, 3, 4)] than in the control rats [ChAT-CT-12+ (Nos. 1, 2, 3)] $(15.288 \pm 3281$ vs. $11.508 \pm 3868$, respectively) (Table 3).

\subsection{Regional Characterization and Distribution of ChAT+ Cells}

Located rostrally in the deeper inner ring of the BF where the transverse fiber systems sweep beneath the accumbens-striatum and pars anterior of the anterior commissure, ChAT + cells are located within the anterior portion of the substantia innominata (SIa). The ChAT + cells in the subcommisural SIa are frequently elongated, multipolar neurons that commonly lie with their long axes parallel to the transverse fibers that travel throughout this

Table 2. Morphometry of choline acetyltransferase-positive $(\mathrm{ChAT}+)$ neurons in the basal forebrain of one aged 12month-old control rat (ChAT-CT-12+ \# 1) and one ALCAR-treated rat (ChAT-ALCAR-12+ \# 2).

\begin{tabular}{ccccc}
\hline \multicolumn{4}{c}{ ChAT-CT-12+ No. 1} & \\
Structure & $\begin{array}{c}\text { No. of } \\
\text { Cells }\end{array}$ & $\begin{array}{c}\text { Small } \\
\text { diameter }\end{array}$ & $\begin{array}{c}\text { Large } \\
\text { diameter }\end{array}$ & $\begin{array}{c}\text { Surface } \\
\text { area }\end{array}$ \\
SIa & 5 & $8.1 \pm 2.2$ & $14.0 \pm 0.9^{*}$ & $99.2 \pm 16.4$ \\
BF & 35 & $10.0 \pm 2.4$ & $16.8 \pm 2.0^{*}$ & $134.5 \pm 37.1$ \\
\hline ChAT-ALCAR-12+ No. 2 & & & \\
Structure & No. of & Small & Large & Surface \\
SIa & Cells & diameter & diameter & area \\
BF & 5 & $8.5 \pm 2.4$ & $15.3 \pm 0.4 *$ & $100.8 \pm 14.7$ \\
\hline
\end{tabular}

1) Measurements in $\mu \mathrm{m}$ and $\mu \mathrm{m}^{2}$ (Mean \pm SD) in the basal forebrain (right site of the brain) for ChAT+ cells in one animal from each group: aged control rat (ChAT-CT-12+ No. 1) and one aged ALCAR-treated rat (ChATALCAR-12+ No. 2) $(16,22,23,24,25)$; 2) Student's t-test for each measurement showed ChAT-CT-12+ cells differed significantly from ChATALCAR-12+ cells in structure and measurements indicated $\left(\mathrm{P}<0.05^{*}\right)$. 
Table 3. Average crude cell counts and average estimated total cholinergic viz. choline acetyltransferase-positive (Ch$\mathrm{AT}+$ ) neurons in the basal forebrain of 12-month-old control rats (ChAT-CT-12+ Nos. 1, 2, 3) and of ALCAR-treated rats (ChAT-ALCAR-12+ Nos. 2, 3, 4).

\begin{tabular}{ccccc}
\hline Structure & $\begin{array}{c}\text { Sites } \\
\text { sampled }\end{array}$ & $\begin{array}{c}\text { Crude } \\
\text { Counts } \pm \text { SD }\end{array}$ & $\begin{array}{c}\text { Estimated } \\
\text { Totals } \pm \text { SD }\end{array}$ & $\begin{array}{c}\text { Probability of } \\
\text { t-test }\end{array}$ \\
\hline \multicolumn{2}{l}{ ChAT-CT-12 } \\
SIp & 2 & $73 \pm$ SD 5* & $1387 \pm 95^{*}$ & $\mathrm{P}<0.05$ \\
Total BF & 6 & $601 \pm 202$ & $11,508 \pm 3868$ & n.s. \\
ChAT-ALCAR-12+ Nos. $2,3,4$ & & \\
SIp & 2 & $103 \pm 19^{*}$ & $1894 \pm 349^{*}$ & \\
BF & 6 & $820 \pm 176$ & $15,288 \pm 3281$ & \\
\hline
\end{tabular}

1) Labeled ChAT + cells on the right side of the brain were plotted from A10.9 to A6.9 $(16,22,23,24,25)$ and their number tabulated for each structure in $25-\mu \mathrm{m}$ thick sections at intervals of $800 \mu \mathrm{m}$. The average crude cell count $( \pm \mathrm{SD})$ and the estimated total number for each structure are presented; 2) The averages of the estimated totals were obtained by multiplying the cell count by the number of sections per interval (32), corrected for the average $\mathrm{BF}$ cell size of each structure and $25-\mu \mathrm{m}$ thick sections at intervals of 800 $\mu \mathrm{m}$, using Abercrombie's formula $(16,22,23,24,25) ; 3)(*)$ Student's t-test showed that there was a significant number of ChAT+ neurons in the substantia innominata pars posterior of the ALCAR- treated rats (ChAT-ALCAR-12+ Nos. 2, 3, 4) in comparison with the control rats (ChAT-CT-12+ Nos. 1, 2, 3)

region. The ChAT+ neurons in the SIa of the 12-month-old control rats were significantly smaller than those in the ALCAR-treated rats, measuring $14.0 \pm 0.9 \mu \mathrm{m}$ vs. $15.3 \pm 0.4 \mu \mathrm{m}$ in long diameter on average $(\mathrm{P}<0.05)[24]$.

Caudally, behind the crossing of the anterior commissure, and dorsally, deep in the magnocellular preoptic nucleus where transverse fibers sweep under the globus pallidus and caudate putamen, ChAT + cells are distributed through the posterior portion of the substantia innominata. Rostrally, the cluster of ChAT cells are oriented in parallel with passing fibers of the stria medullaris and inferior thalamic peduncle, which turn dorsomedially into the rostral pole of the thalamus, and also with the perforating blood vessels which traverse the magnocellular preoptic nucleus to continue through the substantia innominata into the lentiform nucleus. In such aggregates the ChAT+ cells are multipolar neurons that form vertically oriented clusters by parallel alignment of soma and dendrites. We observed more ChAT+ cells in the SIp of the ALCARtreated rats [(ChAT-ALCAR-12+ (Nos. 2, 3, 4)] than in the control rats [ChAT-CT-12+ (Nos. 1, 2, 3)] (on average 1894 vs. 1387, respectively) $(\mathrm{P}<0.05)$ [24].

\section{Discussion}

\subsection{Morris Behavioral Water-Maze Task}

A possible limitation to this study is that we did not evaluate or record the motor performance or the distance traveled in $\mathrm{cm}$ or the time spent in the correct quadrant or the representative trajectories of the two rat groups during swimming performance to find the platform. How- ever, the similarity between the Morris water-maze escape latency times for the aged control and treated rats in this study belong to the category of the so-called "intermediate performer rats" as classified by Taglialatela et al. [13,28] (see Figures 1 and 2).

The behavioral findings of this study strongly indicate and confirm that prolonged treatment with ALCAR can very significantly $(\mathrm{P}<0.0001)$ improve spatial learning and memory on the Morris water-maze test [Freddi et al., 2009]. This study confirmed that the 12-month-old control rats with impaired spatial learning and memory performance on the Morris water-maze test $[13,28]$ had significantly smaller and fewer BF cholinergic neurons than the ALCAR-treated rats [16]. It has been claimed that ALCAR affects the cholinergic central systems through its manifold properties, namely, by increasing the catalyst of L-carnitine acylation to acetyl-L-carnitine, serving as a precursor for acetylcholine, maximizing energy production, promoting cellular membrane stability, counteracting membrane changes, particularly those related to age, and by supporting physiological cellular functioning at the mitochondrial level $[15,13,28,29]$. We suggest that ALCAR treatments from an age of 6 to 12 months can, with various different degrees of impact, counteract agedependent neurodegenerative central and cognitive function changes - and perhaps peripheral motor pathologies which are considerably accelerated during aging. ALCAR treatment during ageing seems to strongly influence the activity of the cholinergic basal complex, so as to facilitate cortical activation, attention, learning and mnemonic processes.

\subsection{Morphology and Estimation of BF ChAT+ Cells}

Our morphological analysis focused on the myelo- and cytostructural BF regions where cholinergic cells are located $[25,26]$. Our results suggest that the average values of the morphological parameters of the ChAT-immunoreactive neurons in the $\mathrm{BF}$ of 12-month-old control rats (ChAT-CT-12) were lower than those of the cholinergic cells observed in the BF of young rats [24] and lower than the cholinergic neurons observed projecting into the meso- and isocortex [22] but similar to the cholinergic cells projecting into the caudal hypothalamus [23]. Interestingly, the large diameter of the ChAT+ cells in the BF of the ALCAR-treated 12-month-old rats was similar to the large diameter of the ChAT+ cells calculated in 518 cholinergic cells in the young control rats [24].

Accurate morphological analysis revealed that the average size of ChAT + neurons in the anterior portion of the substantia innominata of the spatial learning/memoryimpaired control rats was significantly smaller than that in the 12-month-old ALCAR-treated rats. The average of the large diameter of the ChAT + neurons of the substantia 
innominata pars anterior found in the 12-monthold ALCAR-treated rats was similar to the average large diameter of the ChAT + cells in the substantia innominata pars anterior of the young rats [24].

Accurate morphological analysis and estimation of the ChAT cells number revealed that the average estimated number of ChAT + cells throughout the substantia innominata pars posterior of the spatial learning/memory-impaired control rats was significantly lower than that estimated in the 12-month-old ALCAR treated rats (1387 vs. 1894 , respectively; $\mathrm{P}<0.05)$. The number of cholinergic cells estimated in the ALCAR-treated rats was nearly the same as that estimated in the substantia innominata pars posterior in the younger rats (approximately 2182) [24].

Interestingly, ALCAR treatment from the age of 6 to 12 months was found to preserve a large number of cholinergic neurons in the $\mathrm{BF}$ of the rats $(15,288)$. This estimated value is similar to that in the young rats $(18,236$, [24]) and higher than that reported in 21-month-old ALCAR-treated rats $[8,15]$.

Despite differences in immunocytochemical techniques and rat strain and sex, the results of this study do partly agree with previous reports that: 1) there is a reduction in $\mathrm{NGF}+$ /putative-cholinergic neurons in the $\mathrm{BF}$ of rats with longer latency on the spatial water-maze task $[10,11]$ aging causes progressive shrinkage of acetyl cholinoesterase (AChE)-positive neurons in the BF nuclei [20]; 3) there was a 30\% - 50\% reduction in ChAT and AChE activities in the BF [29]; 4) there was a significant reduction in AChE-positive cells in the BF of 24- and 31-month old Wistar rats [16].

To sumarize, treatment with ALCAR in rats aged between 6 and 12 month can significantly boost performance on the spatial learning/memory Morris water-maze task and may importantly and significantly prevent the loss of the mango cellular cholinergic neurons and the change in size within some cholinergic subgroups. The largest diameter of BF cholinergic cells in the 12-month old ALCAR-treated rats was similar to that of the ChAT+ cells in the BF [24], yet similar to those of the cholinergic cells projecting into the prefrontal and parietal cortices [21].

In conclusion, this study confirms that early chronic ALCAR treatment, from the age of 6 months, may better rescue cholinergic neurotransmission which is known to decline with age $[15,22,24,25]$.

\section{Acknowledgements}

The authors wish to thank Sigma Tau for conducting the behavioural studies and administering the pharmacological treatment. No conflict of interest was reported between the authors and Sigma Tau (Italy). Thanks are also due to K. Britsch for reading the manuscript.

\section{REFERENCES}

[1] A. P. Burlina, H. Sershen, E. A. Debler and A. Lajtha, "Uptake of Acetyl-L-Carnitine in the Brain," Neurochemical Research, Vol. 14, No. 5, 1989, pp. 489-493. doi:10.1007/BF00964865

[2] L. Janiri, M. Falcone, A. Persico and E. Tempesta, "Activity of L-Carnitine and L-Acetylcarnitine on Cholinoceptive Neocortical Neurons of the Rat in Vivo," Journal of Neural Transmission, Vol. 86, No. 2, 1991, pp. 135-146.

[3] L. Battistin, G. Pizolato, M. Dam, C. DaCol, C. Perlotto, N. Saitta, N. Borsato, M. Calvani, G. Ferlin, "Single-Proton Emission Computed Tomography Studies with ${ }^{99 \mathrm{~m}} \mathrm{Tc}$ Hexamethylpropyleneamine Oximine in Dementia: Effects of Acute Administration of L-Acetylcarnitine," Europeane Neurology, Vol. 29, No. 5, 1989, 261-265. doi: $10.1159 / 000116423$

[4] A. Carta, M. Calvani, D. Bravi and S. N. Bhuachalla, "Acetyl-L-Carnitine and Alzheimer's Disease: Pharmacological Considerations beyond the Cholinergic Sphere," Annlas of the New York Academy of Science, Vol. 695, 1993, pp. 324-326. doi:10.1111/j.1749-6632.1993.tb23077.x

[5] C. Ori, U. Freo, G. Pizzolato and M. Dam, "Effects of Acetyl-L-Carnitine on Regional Cerebral Glucose Metabolism in Awake Rats," Brain Research, Vol. 951, No. 2, 2002, pp. 330-335. doi:10.1016/S0006-8993(02)03290-0

[6] M. Schieppati, I. Gritti, R. Mazzocchio, A. Rossi and M. Mancia, "Motoneurone Recurrent Inhibition Is Enhanced by L-Acetylcarnitine in Humans," Electromyography and Clinical Neurophysiology, Vol. 29, No. 2, 1989, pp. 7380.

[7] M. Schieppati, I. Gritti and C. Romanò, "Recurrent and Reciprocal Inhibition of the Human Monosynaptic Reflex Shows Opposite Changes Following Intravenous Administration of Acetylcarnitine," Acta Physiologica Scandinavica, Vol. 143, No. 1, 1991, pp. 27-32. doi:10.1111/j.1748-1716.1991.tb09198.x

[8] G. Traina, G. Federighi, M. Macchi, R. Bernardi, M. Durante and M. Brunelli, "Modulation of Myelin Basic Protein Gene Expression by Acetyl-L-carnitine," Molecular Neurobiology, Vol. 44, No. 1, 2011, pp. 1-6.

[9] M. Youle and M. A. Osio, "Double-Blind, Parallel-Group, Placebo-Controlled, Multicentre Study of Acetyl-L-Carnitine in the Symptomatic Treatment of antiretroviral Toxic Neuropathy in Patients with HIV-1 Infections," HIV Medicine, Vol. 8, No. 4, 2007, pp. 241-250. doi:10.1111/j.1468-1293.2007.00467.x

[10] S. Koh and R. Loy, "Age-Related Loss of Nerve Growth Factor Sensitivity in Rat Basal Forebrain Neurons," Brain Research, Vol. 440, No. 2, 1988, pp. 396-401. doi:10.1016/0006-8993(88)91015-3

[11] S. Koh, P. Chang, J. T. Collier and R. Loy, "Loss of NGF Receptors Immunoreactivity in Basal Forebrain Neurons of aged Rats: Correlation with Spatial Memory Impairment," Brain Research, Vol. 498, No. 2, 1989, pp. $397-$ 404. doi:10.1016/0006-8993(89)91125-6

[12] P. Piovesan, L. Pacifici, G. Taglialatela, M. T. Ramacci and L. Angelucci, "Acetyl-L-Carnitine Treatment Increases Choline Acetyltransferase Activity and NGF Levels in the CNS of Adult Rats Following Total Fimbria-Fornix Tran- 
saction," Brain Research, Vol. 633, No. 1-2, 1994, pp. 77-82. doi:10.1016/0006-8993(94)91524-5

[13] G. Taglialatela, A. Caprioli, A. Giuliani and O. Ghirardi, "Spatial Memory and NGF Levels in Aged Rats: Natural Variability and Effects of Acetyl-L-Carnitine Treatment," Experimental Gerontology, Vol. 31, No. 5, 1996, pp. 577587. doi:10.1016/0531-5565(96)00052-6

[14] A. L. Markowska, D. K. Ingram, C. A. Barnes, E. L. Spangler, V. J. Lemken, H. Kametani, W. Yee and D. S. Olton, "Acetyl-L-carnitine 1: Effects on Mortality, Pathology and Sensory Motor Performance in Aging Rats," Neurobiology of Aging, Vol. 11, No. 5, 1990, pp. 491-497. doi:10.1016/0197-4580(90)90109-D

[15] R. Freddi, P. Duca, I. Gritti, M. Mariotti and M. Vertemati, "Behavioural and Degeneration Changes in the Basal Forebrain Systems of Aged Rats: A Quantitative Study in the Region of the Basal Forebrain after Levo-Acetyl-Carnitine Treatments Assessed by Abercrombie Estimation," Progress in Neuro-Psychopharmacology and Biological Psychiatry, Vol. 33, No. 3, 2009, pp. 419-426. doi:10.1016/j.pnpbp.2008.12.021

[16] G. M. Gilad, J. M. Rabey, Y. Tizabi and V. H. Gilad, "AgeDependent Loss and Compensatory Changes of Septohippocampal Cholinergic Neurons in Two Rat Strains Differing in Longevity and Response to Stress," Brain Research, Vol. 436, No. 2, 1987, pp. 311-322. doi:10.1016/0006-8993(87)91675-1

[17] V. N. Luine, K. J. Renner, S. Heady and K. J. Jones, “Age and Sex-Dependent Decreases in ChAT in Basal Forebrain Nuclei," Neurobiology of Aging, Vol. 7, No. 3, 1986, 193-198. doi:10.1016/0197-4580(86)90042-4

[18] J. E. Springer, M. W. Tayrien and R. Loy, "Regional Analysis of Age-Related Changes in the Cholinergic System of the Hippocampal Formation and Basal Forebrain of the Rat,” Brain Research, Vol. 407, No. 1, 1987, pp. 180-184. doi:10.1016/0006-8993(87)91235-2

[19] R. Strong, P. Hicks, L. Hsu, R. T. Bartus and S. J. Enna "Age-Related Alterations in the Rodent Brain Cholinergic System and Behaviour," Neurobiology of Aging, Vol. 1, No. 1, 1980, pp. 59-63. doi:10.1016/0197-4580(80)90025-1

[20] J. C. Hornberger, S. J. Buell, D. G. Flood, T. H. McNeill and P. D. Coleman, "Stability of Numbers but Not Size of Mouse Forebrain Cholinergic Neurons to 53 Months," Neurobiology of Aging, Vol. 6, No. 4, 1985, pp. 269-275. doi:10.1016/0197-4580(85)90003-X

[21] I. Gritti, L. Mainville, M. Mancia and B. E. Jones, "GABAergic and Other Non-Cholinergic Basal Forebrain Neurons Project to Meso- and Iso-Cortical Regions in the Rat," The Journal of Comparative Neurology, Vol. 383,
No. 2, 1997, pp. 163-177. doi:10.1002/(SICI)1096-9861(19970630)383:2<163::AID -CNE4>3.0.CO;2-Z

[22] I. Gritti, L. Mainville, I. Manns and B. E. Jones, "Parvalbumin-, Calbinding- or Caleretinin- in Cortically Projecting and GABAergic, Cholinergic or Glutamatergic Basal Forebrain Neurons of the Rat," The Journal of Comparative Neurology, Vol. 458, No. 1, 2003, pp. 11-31. doi:10.1002/cne.10505

[23] I. Gritti, L. Mainville and B. E. Jones, "Projections of GABAergic and Cholinergic Basal Forebrain and GABAergic Preoptic-Anterior Hypothalamic Neurons to the Posterior Lateral Hypothalamus of the Rat," The Journal of Comparative Neurology, Vol. 339, No. 2, 1994, pp. 251-268. doi:10.1002/cne.903390206

[24] I. Gritti, L. Mainville and B. E. Jones, "Codistribution of GABA- with Acetylcholine-Synthesizing Neurons in the Basal Forebrain of the Rat," The Journal of Comparative Neurology, Vol. 329, No. 4, 1993, pp. 438-457. doi:10.1002/cne.903290403

[25] I. Gritti, P. Henny, F. Galloni, L. Mainville, M. Mariotti and B. E. Jones, "Stereological Estimates of Basal Forebrain Cell Populations in the Rat, Including Neurons Containing Choline Acetyl-Transferase (ChAT), Glutamic Acid Decarboxylase (GAD) or Phosphate-Activated Glutaminase (PAG) and Colocalizing Vesicular Glutamate Transporters (VgluTs)," Neuroscience, Vol. 143, No. 4, 2006, pp. 1051-1064. doi:10.1016/j.neuroscience.2006.09.024

[26] R. Mietinen, G. Kalesnykas and E. H. Koivisto, "Estimation of the Total Number of Cholinergic Neurons Containing Estrogen Receptor- $\alpha$ in the Rat," The Journal of Histochemistry and Citochemistry, Vol. 50, No. 7, 2002, pp. 891-902.

[27] R. G. M. Morris, "Developments of Water-Maze Procedure for Studying Spatial Learning in the Rat," Journal of Neuroscience Methods, Vol. 11, No. 1, 1984, pp. 47-67. doi:10.1016/0165-0270(84)90007-4

[28] G. Taglialatela, D. Navarra, R. Cruciani, M. T. Ramacci, G. S. Alema and L. Angelucci, "Acetyl-L-Carnitine Treatment Increases Nerve Growth Factor Levels and Choline Acetyltransferase Activity in the CNS of Aged Rats," Experimental Gerontology, Vol. 29, No. 1, 1994, pp. 5566. doi:10.1016/0531-5565(94)90062-0

[29] O. Ghirardi, S. Milano, M. T. Ramacci and L. Angelucci, "Effect of Acetyl-L-Carnitine Chronic Treatment on Discrimination Models in Aged Rats," Physiology \& Behavior, Vol. 44, No. 6, 1988, pp. 769-773. doi:10.1016/0031-9384(88)90060-1 